\title{
Incidence of the incorporation of wheat bran in the diet on the rate of passage of the fibre fractions in the rabbit
}

\author{
T Gidenne
}

INRA, Station de Recherches Cunicoles, BP 27, 31326 Castanet-Tolosan, France

The addition of a fibre source in a basal diet could affect the rate of passage (RP) of the diet ingredients and could modify the nutritive value of the diet, as demonstrated for ruminants. The aim of this study was to investigate in the rabbit the effect of the wheat bran (WB) incorporation level in a basal concentrate diet (BD) on the RP of the fibre fractions from WB and $\mathrm{BD}$.

The wheat bran was incorporated at 4 levels $(0-20-40-60 \%)$ in a basal diet mainly composed of wheat $(60 \%)$, wheat straw $(15 \%)$ sunflower and soybean meal (22\%). The 4 diets were similar in crude protein content $(17.5 \%)$ and ADF content (14.1\%), and differed mainly in their NDF content (27.7-31.6-36.4-41.3\% DM respectively from 0 to $60 \%$ WB incorporation), and the diets were given on ad libitum basis to 4 groups of 7 New Zealand white rabbits ( 8 weeks old). The fibre particles of BD and WB were labelled with 169 Ytterbium and 141 cerium, respectively (Beeber and Ellis, 1985), in order to obtain simultaneous but separate RP measurement. The 2 types of labelled particles were given orally as a single dose at $9.30 \mathrm{am}$, and the mean retention time (MRT) in the whole digestive tract was calculated as follows: MRT $=\Sigma m_{i} t / \Sigma m_{i}\left(m_{i}=\right.$ quantity of marker excreted in feces, at the time $t_{\text {) }}$.

During the MRT measurements, the mean feed intake was respectively $88.9,90.5,103.0$ and $102.5 \mathrm{~g} \mathrm{DM} / \mathrm{d}$ from 0 to $60 \%$ WB incorporation, and a significant difference $(P<0.05$, SEM $=4.1$ ) was detected only when comparing the diets ' 0 and $20 \%$ ' with ' $40-60 \%$ WB (contrast method). The MRT of the 2 fibre fractions (WB and BD) were not different $(P<0.99)$ whatever the level of WB. The MRT was reduced significantly as the incorporation of WB increased. This shortening in MRT was correlated with the dry matter intake $(\mathbb{R}=0.59, n=19)$ and particularly with the quantity of NDF ingested $\left(r^{2}=0.69\right)$. The transit time (mean $=4.3 \mathrm{~h}$ ), defined as the first appearance of the marker in feces, was not affected by the incorporation level of WB ( $P<$ 0.71 ), and it did not differ between the 2 fibre fractions.

Beever DE, Ellis WC (1985) Proc Nutr Soc 44, 117A

Table I. Mean retention time (h) of the fibre fraction from wheat bran and basal diet.

\begin{tabular}{|c|c|c|c|c|c|c|}
\hline \multirow[t]{3}{*}{ MRT } & \multicolumn{4}{|c|}{ Incorporation rate of wheat bran (\%) } & \multirow[b]{3}{*}{ SEM } & \multirow[b]{3}{*}{ P level } \\
\hline & 0 & 20 & 40 & 60 & & \\
\hline & $(n=4)$ & $(n=5)$ & $(n=6)$ & $(n=4)$ & & \\
\hline Basal diet ( $\left.{ }^{169} Y \mathrm{~b}\right)$ & $31.8^{a}$ & $27.3^{\mathrm{ab}}$ & $23.0 \mathrm{ab}$ & $21.0^{b}$ & 1.7 & 0.031 \\
\hline Wheat bran $\left({ }^{141} \mathrm{Ce}\right)$ & - & 27.4 & 23.0 & 20.7 & 2.1 & 0.073 \\
\hline
\end{tabular}

